\title{
PREDICTING THE BEHAVIORAL DEPENDABILITY OF SPORT EVENT VOLUNTEERS
}

\section{GRAHAM CUSKELLY,* CHRISTOPHER AULD $\dagger \dagger$ MAUREEN HARRINGTON,$*$ and DENIS COLEMAN $\$$}

\author{
*Griffith University, Brisbane, Australia \\ $\dagger$ University of Hong Kong, Hong Kong, China \\ $\$$ Victoria University, Melbourne, Australia
}

\begin{abstract}
The dependability of volunteers in completing work assignments can impact upon the financial and operational success of major sport events and presents a significant challenge for event organizers. Despite the short-term nature of many events and the apparently manageable level of commitment, volunteers sometimes exhibit less than satisfactory levels of compliance to assigned tasks. Based on the theory of planned behavior (TPB), this study examined the behavioral dependability of operational-level volunteers at major sport events. A preevent and postevent survey protocol was used to gather data from volunteers $(n=391)$ at five events. The study measured the attitudes and beliefs of event volunteers and their self-reported level of behavioral dependability. Using multiple regression analysis, the study found that a number of attitudinal beliefs about volunteering, subjective norms, and perceived behavioral control predicted behavioral dependability. It was concluded that the TPB was a useful theoretical framework for conceptualizing and predicting the behavior of major event volunteers but the generalizability of these findings was limited because the significant predictors of dependability were not consistent across all of the events studied.
\end{abstract}

Key words: Behavioral dependability; Volunteers; Sport events; Predictors

Volunteer labor is critical to the operational and financial success of many major sport events. This is evident in the size of the volunteer staffing component of events. Even with a total budget of \$AUD2.8 billion, the Sydney Olympic Games required the assistance of more than 40,000 volunteers (Sydney Organizing Committee for the Olympic Games [SOCOG], 2000). Sport events on a smaller scale also require large numbers of volunteers. For example, Rally Australia uses over 1500 volunteers (P. Reed, personal communication, January 15, 2001) and the 2001 Goodwill Games in Brisbane used the services of 3500 volunteers (Goodwill Games, 2001).

A problem for major event organizers is the level of dependability of volunteers. Pearce (1993) stated that "complaints about the work performance of volunteers are frequent enough that the matter deserves serious attention ... [and that] ... organizations do not press 
their volunteers to maintain work standards" (p. 84). More recently, Howden (2003) reported that approximately $25 \%$ of volunteers either did not report for duty or left their posts during test events for the Athens 2004 Olympic Games. Volunteers who do not show up for a shift assignment or who fail to complete assigned tasks can cause operational problems for event organizers and other volunteers. However, there is a tendency for event organizers to only view volunteers as a source of unpaid labor rather than develop an understanding of the factors that may influence volunteers to assist in the delivery of an event and complete assigned tasks. With the operational, financial, and time pressures involved in staging major events, organizers have little time to reflect on what makes volunteers dependable. In contrast to the management of paid labor, event organizers tend to "over-recruit" volunteers to compensate for an anticipated lack of dependability. Recruiting more volunteers than necessary may be an effective way to cover the myriad of tasks associated with staging a major event, but it has inherent disadvantages. Higher volunteer numbers can lead to increased costs in selection and placement, orientation and training, uniforms, transport, meals, and recognition programs. As well, an oversupply of volunteers may lead to dissatisfaction among underutilized volunteers.

The work conditions of major sport event volunteers contrast markedly with those of volunteers found in other settings such as community sport organizations. The routinized elements of event volunteering make it more like paid work than other forms of sport volunteering. For example, major events are often staged over a limited number of days with inflexible deadlines making volunteer work intensive and highly formalized. Volunteers are assigned specific tasks at particular days and times and may be required to complete a high number of hours over a short period of time. For example, the majority of Sydney 2000 Olympic Games volunteers were required to complete a minimum of 10 shifts each of 8 hours over the 16 days of the Games (personal observation, 2000). Major sport event volunteers often have to rearrange family and work commitments to fit in with the demands of event organizers. In contrast, volunteers in community sport organizations seem to exercise more control over their unpaid work. Organizational demands on their time are less intense and they are more likely to be able to schedule their volunteer work to fit in with existing family and work commitments. Over a 12-month period, sport volun- teers in community settings completed a median of 60 hours of volunteer work (Australian Bureau of Statistics, 1996), whereas Sydney Olympic Games volunteers completed a minimum of 80 hours of volunteer work over 16 days.

Despite the importance of volunteers in the staging of major sport events, little is known about the social and cognitive processes that influence individuals to volunteer for such events or to complete their shift assignments during the staging of an event. Farrell, Johnston, and Twynam (1998) found evidence that major event volunteers are a distinct category of volunteers who seek to satisfy particular motives through their volunteer involvement in special events. Furthermore, they argued "it is vital that organizers understand volunteer motivation and their satisfaction with the volunteering experience in order to respond effectively to management needs in the areas of recruitment, retention, and daily operations" (Farrell et al., 1998, pp. 288-289). While important, these findings do not provide insights into the actual behavior of volunteers. The purpose of this study was to build on this earlier work by examining what predicted the behavioral dependability of volunteers at a number of major sport events.

\section{Theoretical Background}

A better understanding of behavioral dependability is likely to be found in an examination of the antecedent social and cognitive processes that influence volunteers to give up their free time for a sport event. Several theories of determinants of behavior could assist in this task. Social cognition and persuasive communication theories such as self-efficacy theory (Bandura, 1986), process model of attitudes (Fazio, Powell, \& Herr, 1983), the elaboration likelihood model of persuasion (Petty \& Cacioppo, 1986), and the theory of planned behavior (TPB) (Ajzen, 1991) were considered as possible theoretical frameworks for this study.

However, the TPB that is based on the earlier theory of reasoned action (TRA) was utilized in the present study because it has been well supported empirically, particularly when the behavior of interest is identified in terms of action, target, context, and time (Fishbein \& Manfredo, 1992). Applying these terms, this study examined operational volunteers (context) completing shift assignments (action) during a specific major sport event (target), which commenced within the ensuing 2 weeks (time). While determinants of some behaviors 
have been investigated under laboratory and experimental conditions, for the most part the TPB has been used in the field to study behaviors of appreciable social and personal significance and has been used to predict a wide range of behaviors including alcohol use, financial investments, participation in physical activity, shoplifting, condom use, breast screening, driving behavior, eating healthy foods, and wearing safety helmets (e.g., Astrom \& Rise, 2001; East, 1993; Godin, 1994; Hausenblas, Carron, \& Mack, 1997; Hill, Mann, \& Wearing, 1996; Johnston \& White, 2003; Kashima, Gallois, \& McCamish, 1993; Maddux, 1993; Norman \& Bonnett, 1995; Parker, Manstead, Stradling, \& Reason, 1992; Quine, Rutter, \& Arnold, 2001; Steadman, Rutter, \& Field, 2002; Tonglet, 2002).

The TPB is based on the concepts of personality traits and attitudes and how individuals plan and execute their behavior in accordance with these (Ajzen, 1988). This theory argues that an individual's intention to perform a given behavior is the most immediate determinant of behavior. Concerned with the causal antecedents of behavior, the TPB posits that intentions are a function of attitudinal beliefs (AB) toward the behavior, subjective norms (SN), and perceived behavioral control (PBC). A person's attitude towards a particular behavior is a function of their salient beliefs that the action will lead to certain positive or negative outcomes and an evaluation of how important these outcomes might be. The subjective norm is a person's perception of the collective social pressure exerted by salient individuals or groups (referents) to engage in a particular behavior (Ajzen, 1988, p. 121). The subjective norm is influenced by the extent to which a person believes that important referents would approve or disapprove of a particular behavior and the person's motivation to comply with the referent in question. Engaging in a particular behavior is also dependent on the level of perceived behavioral control an individual has over their actions (Fig. 1).

Most intended behaviors are goals "whose attainment is subject to some degree of uncertainty" (Ajzen, 1988, p. 128). The degree of uncertainty is influenced by the presence or absence of requisite resources and opportunities that are called control factors. Ajzen (1988) categorized the control factors as internal (information, skills and abilities, emotions and compulsions) and external (opportunity and dependence on others). People who believe that they have neither the resources nor the opportunities to engage in a particular behavior are unlikely to form a strong intention to do so even if they believe that important referents (e.g., friends and family) would approve and they hold positive beliefs about the outcomes of that behavior.

The extent of behavioral control can influence behavior either directly or indirectly through behavioral intentions. Under conditions when behavioral control reflects actual capacity to control, then behavior can be predicted independently of behavioral intention, as

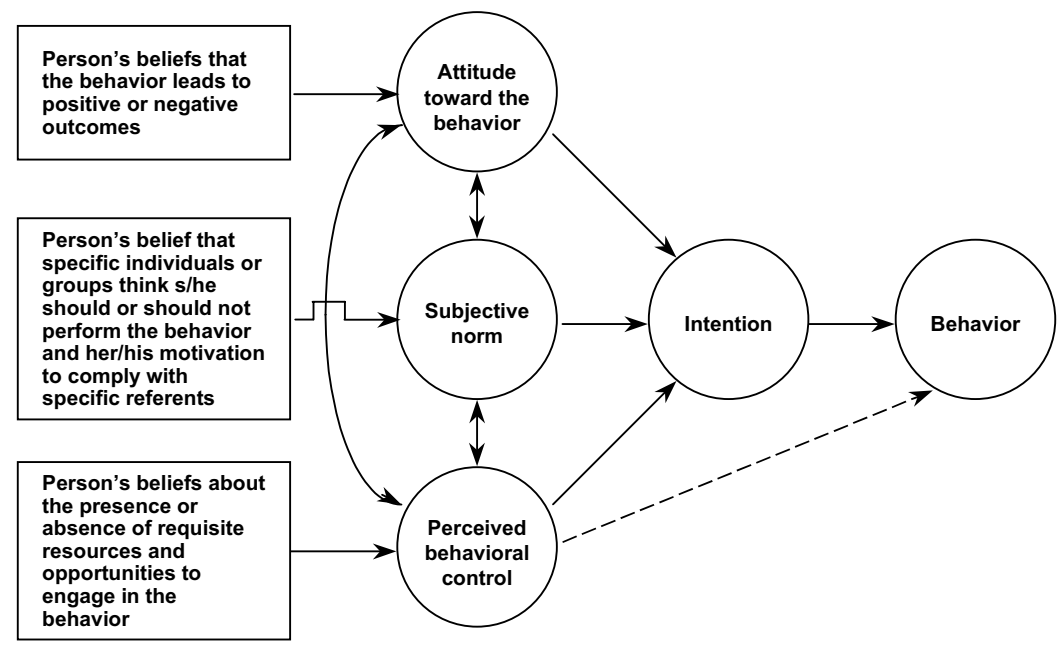

Figure 1. The theory of planned behavior and the influence of behavioral, normative, and control beliefs (from Ajzen, 1988; Ajzen \& Fishbein, 1980). 
shown in Figure 1. However, when the capacity to control is essentially perceived it is more likely to influence the occurrence of the behavior by modifying the person's intentions.

\section{Application of the Theory of Planned Behavior to Volunteering}

The TPB and the TRA have been applied to leisure behavior, which, like many forms of volunteering, may be considered as a free-choice behavior. Unlike volunteering, however, most leisure behavior is not necessarily directed towards beneficiaries other than oneself. Ajzen and Driver (1991, 1992a, 1992b) have been the most prominent researchers in this area. For example, they found that leisure participation was influenced by behavioral, normative, and control beliefs (Ajzen \& Driver, 1991) and that involvement did not affect the accuracy of predicted behavioral intentions (Ajzen \& Driver, 1992a). In another study, Ajzen and Driver (1992b) found that ethical and moral considerations influenced willingness to pay a fee to participate in selected leisure activities. A study of national park visitors' beliefs by Brown (1999) found that attitudes towards the behavior and subjective norms predicted behavioral intentions and participation in a culturally inappropriate tourism activity. In sport, the TPB has been applied mostly to predicting exercise adherence, physical activity, and training behavior (e.g., Biddle \& Nigg, 2000; Bozionelos \& Bennett, 1999; Courneya, Bobick, \& Schinke, 1999; Mummery \& Wankel, 1999; Palmer, Burwitz, Smith, \& Collins, 1999; Rosen, 2000).

The TPB has not been applied extensively to the behavior of volunteers in community agencies nor in other organizational settings. There is little evidence of the application of any of the major theoretical components of the TPB being tested empirically amongst volunteers. Other than studies by Harrison (1995) and Warburton and Terry (2000), which researched volunteers in settings quite different to major sport events, there has been little application of the TPB to the study of volunteers.

The TPB can be readily applied to volunteering to assist in sport events. In deciding to volunteer for a major sport event, an individual may have formed the belief that volunteering will lead to positive outcomes that outweigh possible negative outcomes. They may have also canvassed the opinions of referents (e.g., friends, families, other volunteers) about whether they should volunteer and weighed the extent to which they are motivated to comply with the opinions of those referents. They may also have considered the extent to which they believe they can successfully control the degree of ambivalence about being a volunteer. Such feelings may stem from internal factors (e.g., having the skills needed to volunteer) or from external factors (e.g., having the support of event staff).

The studies listed above support the relevance of the TPB in explaining various aspects and forms of voluntary behavior. Furthermore, they highlight the importance of moral considerations, but provide little guidance for understanding or predicting major event volunteer behavior. The following section reviews the findings of several studies of event volunteers that have potential to inform research into major event volunteers using the TPB.

\section{Volunteers and Major Events}

Volunteers at major events have been the subject of several studies, which have examined motives, expectations, and satisfaction. Based on the work of Caldwell and Andereck (1994), Farrell et al. (1998) stated that "motivation for special event volunteers is different from that for other volunteers" (p. 285). This was supported by Johnston, Twynam, and Farrell (2000), who reported that the motivation of event volunteers includes dimensions uniquely linked to the special event (e.g., sport involvement). Furthermore, Saleh and Wood (1998) reported in a study of volunteers at a multicultural event that while many of the motives of the event volunteers were similar to those of volunteers in community and social services, they were also "strongly motivated by cultural factors" (p. 69) specific to this type of event. These included, for example, to share their culture with others and to maintain their own cultural links. Andrew (1996) concluded from his study of a "large scale sports event" that "individuals will be attracted by and expect different material and personal incentives when volunteering" (p. 24). Farrell et al. (1998) also argued that volunteer satisfaction was related to the facilities and organization of the event and suggested that these are areas over which managers have considerable control. This is consistent with Elstad (1996), who found in a study of student volunteers at the Lillehammer Winter Olympics that the most positive factors associated with satisfaction were expanding personal networks, being part of the event atmosphere, and achieving job-related 
competence. The strongest negative factors were transport, food, accommodation, and job characteristics (e.g., stress, too little or too much to do, long working days). These studies are helpful in understanding the motives, expectations, and satisfaction of event volunteers but, beyond speculation, do not specifically address behavioral implications for event volunteers.

\section{Behavioral Dependability}

Volunteers, like other event staff, display varying levels of dependability. Volunteers may fail to attend assigned shifts or complete their assigned tasks. In this study, "behavioral dependability" is the extent to which the attendance and on-the-job behavior of major event volunteers meets or exceeds the expectations of event organizers. Assuming that volunteers are rostered for particular days and times, event organizers can reasonably expect that volunteers will complete the work shifts or hours to which they have agreed or that they would, if permitted, arrange for a suitable substitute. Event organizers might also reasonably expect that volunteers would start and finish their rostered shifts on time and complete all assigned tasks. Starting and finishing on time and completing all assigned tasks during scheduled shifts might be considered a minimal standard of behavioral dependability. However, because event organizers cannot anticipate and plan for all contingencies during a major event they are reliant on volunteers performing at higher levels of behavioral dependability. Therefore, behavioral dependability may also be considered more than meeting the minimum expectations of event organizers. Higher levels of behavioral dependability are indicated by willingly undertaking additional shifts or hours to cover for others who have not shown up or by undertaking additional tasks on their own initiative or when asked by a supervisor.

Dependability may be associated with volunteer rewards and incentives that may be intrinsic or extrinsic in nature. Pearce (1993) argued that volunteers derive their rewards from participating in the act of volunteering itself. Volunteers are not paid for what they do and volunteering is legitimized by emphasizing its work facet (Pearce, 1993). This implies that volunteers receive rewards for their work in much the same ways as employees receive pay. However, the rewards for volunteering "that seem most important are not under the control of the organization but derive from the partici- pation itself" (Pearce, 1993, p. 181). Volunteering is motivated by enjoyment of the activity, social interaction, and satisfaction with contributing to the larger social good (Pearce, 1993).

Green and Chalip (1998) argued that the decision to volunteer is a leisure choice and that the recruitment and retention of volunteers for sport events is essentially a marketing problem. Access to the backstage, being an insider, having opportunities to meet athletes and to socialize with executives and event staff, as well as tangible forms of reward, recognition, and status (e.g., uniforms, badges, pins, and plaques), are important benefits for event volunteers (Green \& Chalip, 1998). This approach assumes that volunteering is an exchange relationship, which is at odds with the views of Pearce (1993). The source of these different viewpoints may be contextual in that Green and Chalip (1998) based their findings on high-profile national and international events whereas Pearce (1993) focused on community organizations. Further evidence of the contextual rewards of volunteering comes from one of the major events that was part of the current research. Volunteers at the V8 Supercar Shell Championship Series motor sport event expressed a level of dissatisfaction with the lack of recognition and absence of material support (volunteers were only supplied with food and drinks) afforded by race organizers. In the context of the commodity-intensive serious leisure pursuit of motor sport racing, the specialized and necessary work of the amateur/volunteers made the event possible, and yet, unlike the organizers, racing teams, media, and commodity producers, the volunteers were the only ones not to receive material benefits from the event (see Harrington, Cuskelly, \& Auld, 2000).

Objective measures of behavioral dependability could be obtained through a third party's (e.g., volunteer supervisor) rating of the extent to which each volunteer's performance matched or exceeded the expectations of event organizers or by comparing volunteer attendance records with volunteer rosters. Although independent, such a simple comparison does not fully capture the essence of behavioral dependability, as conceptualized in this study. It is limited by the accuracy of rosters and attendance records and the extent to which volunteer supervisors know the volunteers in their work teams and can observe the on-the-job performance of their volunteers. In subjective terms, event volunteers could rate their own performance against a set of criteria designed to self-report perceived levels of dependability. 
The latter approach was adopted in this study to overcome the limitations of what might be considered more objective observations.

Although there is a growing research literature about event volunteers and their motives, there is a paucity of research examining the behavior (specifically dependability) of volunteers. Perhaps there is little to be gained in debating the source or value of rewards, unless there is a clearer understanding of the more fundamental question of the social and cognitive processes that underlie the beliefs and attitudes of volunteers and their subsequent behavior. For the most part, previous studies (e.g., Andrew, 1996; Elstad, 1996; Farrell et al., 1998; Johnston et al., 2000) have researched event volunteers' motives and satisfaction within the context of a single event. This research approach has certain limitations as it falls short of explaining why some volunteers are more dependable than others despite sharing similar motivations. It is also important to understand the extent to which volunteers' beliefs, attitudes, and behaviors, and the relationships between these factors, are generalizable across a range of events and thus the study should be replicated in differing kinds of sport events.

In this study, it is assumed that a decision to volunteer was rational (an assumption inherent in the TPB), made without coercion, that volunteers took into consideration salient beliefs about event volunteering, opinions of referents, motivation to comply with referents, and perceptions about the degree of control they might have over the experience. Volunteers are found at both managerial and operational levels at most major sport events, with the largest numbers of volunteers usually occupying operational level positions. In this study, operational level volunteers were defined as those volunteers who were deployed on a day-to-day basis, to specific tasks immediately preceding (setup), during, and following (pack up) an event. A major sport event was defined as a national or international sport event, which was conducted over more than 1 day and deployed a minimum of 150 volunteers in operational positions. This definition is consistent with the event framework (core and qualifying criteria) developed by Jago and Shaw (1998).

The study examined the influence of the major components of the TPB in predicting the behavioral dependability of major sport event volunteers. Because the TPB is concerned with the causal antecedents of behavior, conditions found to influence behavioral dependabil- ity and that can be controlled by event organizers (e.g., work conditions) have the potential to alter volunteer management practices at major events. Causal antecedents that are controlled by the volunteers themselves (e.g., attitudes) may be helpful in the design of recruitment and screening practices used by event organizers.

Methods

\section{Sample}

Five major events were selected to represent a range of characteristics such as single and multisport events, annual and one-off events, and events organized by the government, private, and not-for-profit sectors. The participants in this study were operational-level volunteers who had each accepted a voluntary position at one of these events. A total of 842 volunteers were invited (see Procedures) to participate in the study by completing a preevent questionnaire and a second, postevent questionnaire. Of those invited, 649 returned useable preevent questionnaires $(77 \%)$ and 443 returned useable postevent questionnaires (52.6\%).

The study participants were predominantly male (58\%), Australian born (80\%), had completed at least a high school education (36\%), and were employed fullor part-time (70\%). The mean age of the study participants was 41.2 years. The participants were rostered for a mean of 36 hours during the event and completed a mean of 42 volunteer hours during the staging of their event. The participants also completed a mean of 13 additional hours of orientation and training prior to the staging of their event.

\section{Measures}

The preevent questionnaire consisted of five major sections. It gathered data about participation as a volunteer for the event (e.g., hours and shifts rostered). It also measured determinants identified in the TPB including: attitudes about volunteering for the event (attitudinal beliefs); the influence of significant others or referents in deciding to volunteer for the event (subjective norms); and perceptions about the level of control volunteers felt they would have over their event experience (perceived behavioral control). Another section of the survey measured demographic variables (e.g., age, sex, education, occupation, income). Intention to complete rostered hours or shifts was also measured in the preevent survey. The postevent questionnaire was 
used to gather data about the participants self-reported level of behavioral dependability in the major event.

The items designed to measure the components of the TPB were developed following a detailed set of procedures for conducting an elicitation study (Ajzen \& Fishbein, 1980, pp. 68-70). An elicitation study is considered necessary for behaviors or populations that have not been studied previously within the context of the TPB. The purpose of the elicitation study was to gather salient beliefs about attitudinal beliefs, subjective norms, and perceived behavioral control of sport event volunteers. Semistructured telephone interviews averaging 30 minutes each were conducted with a random sample of 30 volunteers selected from the Asia Pacific Masters Games. The preevent questionnaire was pilot tested with a convenience sample of 120 volunteers at a Queensland State (Provincial) Surf Life Saving Championship prior to implementation in the main study. Only minor adjustments to the questionnaire wording were required as a result of the pilot study.

Attitudinal beliefs (AB) were measured in accordance with specifications devised by Ajzen and Fishbein (1980), by seeking reactions of the volunteers to 25 positive or negative outcome beliefs about their volunteering. The responses used 5-point Likert items (1 "strongly disagree" to 5 "strongly agree"). Subjective norms (SN) were also measured in accordance with specifications devised by Ajzen and Fishbein (1980) by multiplying responses on two separate sets of 5-point Likert items: encouragement and influence. First, the volunteers were asked to indicate their beliefs about whether they were encouraged or discouraged by 14 separate referents (e.g., spouse, children, event advertising) to volunteer ( -2 "strongly discouraged" to +2 "strongly encouraged"). Second, study participants were asked to indicate their beliefs about how influential each of the same referents were in their decision to volunteer ( 1 "not at all influential" to 5 "extremely influential"). Subjective norm scores were calculated by multiplying the encouragement response by the influence belief scale response for each of the 14 referents for each participant. Scores could range from -10 (strong negative influence) to +10 (strong positive influence). Expressions of perceived behavioral control (PBC) were measured in accordance with specifications devised by Ajzen and Fishbein (1980). This section comprised 20 statements about volunteers' perceptions of the internal (information, skills and abilities, and emotions and compulsions) and external (opportunity and dependence on others) control factors. The responses used 5-point Likert items (1 "strongly disagree" to 5 "strongly agree").

Behavioral dependability was a composite measure that used a number of self-reported behavioral indicators associated with shifts and hours worked, overall dependability, and specific dependability. In the preevent questionnaire two separate questions asked participants to provide or estimate the total number of shifts and the total number of hours they were rostered or expected to complete during the event. The postevent questionnaire asked participants to recall the total number of shifts and the total number of hours they had volunteered during the event. Ratios of completed shifts or hours to rostered shifts or hours, respectively, provided two estimates of behavioral dependability. A single global dependability item asked participants to estimate the extent to which they felt they could be depended upon during the staging of the event. Responses could range from 1 "not dependable" ("I completed substantially less hours than I was expected to do") to 5 "very highly dependable" ("I completed substantially more hours than I was expected to do"). Participants were also asked to respond to a total of eight statements that used 4-point Likert responses ( 1 "not at all" to 4 "at all times"). Statements gathered self-reported measures of task completion, shift arrival (e.g., "I arrived on time for the shifts I was rostered for") and departure times, covering for absent volunteers, and completing additional tasks (e.g., "I stayed longer than my rostered shift times to cover for volunteers who did not turn up for their shifts").

\section{Procedure}

The sport events, which ranged in duration from 4 to 11 days, were the Arafura Games (a biennial international multisport event), the Federation Internationale Hockey Champions (FIH) Trophy, the Queensland 500 (Q500) V8 Supercar Shell Championship Series (a motor race), the Noosa International Triathlon (Noosa Tri) (an International Triathlon Union-sanctioned event), and the Australian Professional Golfers' Association (PGA) Championship.

Preevent Survey. The names and addresses of participants were selected from databases provided by the event organizers. At events with 200 volunteers or fewer, 
all volunteers were invited to participate in the study. At events where there were more than 200 volunteers, a sample of 200 volunteers was randomly selected to participate in the study. Participation in the study was voluntary and personal details were stored separately from the completed questionnaires to ensure the confidentiality of respondents.

A package consisting of preevent questionnaire, cover letter, informed consent proforma, and reply paid return envelope was mailed to the study participants between 10 and 14 days prior to the staging of the event. A follow-up postcard reminding participants to complete and return the preevent questionnaire was mailed 5 to 7 days after the initial mailing. As well, a member of the research team attended each event during the final preparations and for the first day of each event to follow up with volunteers who had not returned preevent questionnaires.
Postevent Survey. Within 14 days of the conclusion of the event, a postevent questionnaire was mailed out to the participants who had completed and returned a useable preevent questionnaire. A follow-up postcard reminding participants to complete and return their postevent questionnaire was mailed 5 to 7 days after the initial mailing. Pre- and postquestionnaires were numbered to ensure data from both questionnaires could be matched on a case-by-case basis.

\section{Data Analysis}

Data for the participants who provided useable preevent and postevent questionnaires were matched and entered on a case-by-case basis into an SPSS data file. The data were checked for outliers (more than \pm 3 SD), and invalid values (e.g., reported hours in excess of available volunteer hours) and were dropped from

Table 1

Rotated Factor Loadings for Attitudinal Beliefs Subscales, Cronbach Alpha Reliability Coefficients, Means and SDs

\begin{tabular}{|c|c|c|c|c|c|}
\hline \multirow[b]{2}{*}{ Factor/Item } & \multicolumn{5}{|c|}{ Rotated Factor Loadings ${ }^{\mathrm{a}}$} \\
\hline & 1 & 2 & 3 & 4 & 5 \\
\hline \multicolumn{6}{|l|}{ 1. Negative affect $(\alpha=0.79 ;$ mean $=3.23 ; \mathrm{SD}=0.75)$} \\
\hline I may feel obligated to put in an unreasonable number of hours & 0.74 & & & & \\
\hline $\begin{array}{l}\text { I may have to work as hard as many paid staff but will probably have poorer working } \\
\text { conditions than paid staff }\end{array}$ & 0.73 & & & & \\
\hline I may have to endure long hours doing boring and mundane tasks & 0.71 & & & & \\
\hline I may experience heavy workloads and high levels of stress & 0.69 & & -0.32 & & \\
\hline I may incur financial costs that are not likely to be reimbursed by the event organizers & 0.67 & & & & \\
\hline I might feel as though I am being taken advantage of by the event organizers & 0.58 & 0.32 & & 0.35 & \\
\hline \multicolumn{6}{|l|}{ 2. Positive affect $(\alpha=0.75 ;$ mean $=4.13 ; \mathrm{SD}=0.47)$} \\
\hline I expect to feel good about being able to help others & & 0.83 & & & \\
\hline I anticipate that I will enjoy being active and involved in a community event & & 0.82 & & & \\
\hline I anticipate that I'll feel good about using my free time in a constructive way & & 0.70 & & & \\
\hline I expect to feel as though I've put something back into sport & & 0.59 & & & \\
\hline $\begin{array}{l}\text { I will probably receive some tangible benefits such as free uniforms or shirts, meals, event tickets, } \\
\text { and parking }\end{array}$ & & 0.51 & & & 0.36 \\
\hline \multicolumn{6}{|l|}{ 3. Employment benefits $(\alpha=0.67$; mean $=3.34 ; \mathrm{SD}=0.92)$} \\
\hline I may gain valuable experience that might help with future paid employment & & & 0.81 & & \\
\hline I expect that I will learn and develop new skills & & 0.30 & 0.76 & & \\
\hline \multicolumn{6}{|l|}{ 4. Feeling undervalued $(\alpha=0.51 ;$ mean $=3.54 ; \mathrm{SD}=0.82)$} \\
\hline I might be seen as getting in the way of efficient event management & & & & 0.80 & \\
\hline I most probably will feel as though I am neither valued, needed, or respected & & & & 0.61 & \\
\hline I might be bossed about by supervisors who do not have a good understanding of my role & 0.38 & & & 0.57 & \\
\hline \multicolumn{6}{|l|}{ 5. Insider benefits $(\alpha=0.54 ;$ mean $=4.05 ; \mathrm{SD}=0.64)$} \\
\hline I expect to be much "closer to the action" than most spectators & & & & & 0.79 \\
\hline I expect to "rub shoulders" with star athletes or celebrities & & & & & 0.75 \\
\hline Eigen values & 4.1 & 3.1 & 1.2 & 1.2 & 1.1 \\
\hline Variance explained $(\%)$ & 22.7 & 17.1 & 6.6 & 6.5 & 6.1 \\
\hline Cumulative variance explained (\%) & 22.7 & 39.8 & 46.4 & 52.9 & 59.0 \\
\hline
\end{tabular}

${ }^{\mathrm{a}}$ Factor loadings $<0.3$ have been suppressed. 
the analysis process. Cases with missing data were also dropped, thus reducing the data available for analysis from 443 cases to 391 cases. The behavioral intentions variable was dropped from the data analysis process when it was found that $97 \%$ of the participants answered that they intended to complete all of their shift assignments.

To reduce the number of observed variables, the items that comprised the attitudinal beliefs, subjective norms, and perceived behavioral control scales (independent variables) and behavioral dependability (dependent variable) were subjected to four separate exploratory factor analyses (principal components analysis and varimax rotation). Because of the low variable to case ratio and to meet the "general rule of thumb ... [of] . . . at least 300 cases for factor analysis" (Tabachnick \& Fidell, 2001, p. 588) it was not possible to factor analyze each of the scales separately for each of the five sport events. Therefore, the data from all 391 cases were factor analyzed together for each of the four scales. The results of these factor analyses are displayed in Tables 1 to 4 along with Cronbach alpha reliability coefficients and mean scores for each factor.

Five interpretable factors were extracted from the attitudinal beliefs scale and accounted for $59 \%$ of the cumulative variance (Table 1). The five factors were labeled negative affect, positive affect, employment benefits, feeling undervalued, and insider benefits. Seven of the 25 scale items loaded on more than one factor (e.g., "I expect to find that my volunteer work is enjoyable," and "I am likely to be seen by others as competent at my tasks") and were dropped from the analysis. Four interpretable factors were extracted from the subjective norms scale and accounted for $70.8 \%$ of the cumulative variance (Table 2). The factors were labeled event staff/volunteers, distal influences, proximal influences, and event attractions. Three of the 14 subjective norms items loaded on more than one factor ("my spouse or partner," "my parents," and "friends and acquaintances in other community based organizations where I already volunteer") and were dropped from the analysis. Five interpretable factors were extracted from the perceived behavioral control scale and accounted for $61.9 \%$ of the cumulative variance (Table 3 ). The five factors were labeled work conditions, confidence/skills, skills matched, lack of choice about hours, and other commitments. Three of the 20 scale items loaded on more than one factor (e.g., "I will receive or have had adequate orientation for my major responsibilities") and were dropped from the analysis.

Table 2

Rotated Factor Loadings for Subjective Norms Subscales, Cronbach Alpha Reliability Coefficients, Means and SDs

\begin{tabular}{|c|c|c|c|c|}
\hline \multirow[b]{2}{*}{ Factor/Item } & \multicolumn{4}{|c|}{ Rotated Factor Loadings ${ }^{\mathrm{a}}$} \\
\hline & 1 & 2 & 3 & 4 \\
\hline \multicolumn{5}{|l|}{ 1. Event staff/volunteers $(\alpha=0.74 ;$ mean $=1.26 ; \mathrm{SD}=1.60)$} \\
\hline The managers and staff of other major events where I have volunteered & 0.86 & & & \\
\hline Volunteers at other major events where I have volunteered & 0.81 & & & \\
\hline Volunteers who had already volunteered for this event & 0.67 & & & \\
\hline The managers and staff of this major sport event & 0.55 & & & \\
\hline \multicolumn{5}{|l|}{ 2. Distal influences $(\alpha=0.78 ;$ mean $=0.58 ; \mathrm{SD}=1.37)$} \\
\hline My colleagues where I work & & 0.90 & & \\
\hline My supervisor or boss where I work & & 0.90 & & \\
\hline My close friends outside of sport & & 0.56 & 0.34 & \\
\hline \multicolumn{5}{|l|}{ 3. Proximal influences $(\alpha=0.86 ;$ mean $=0.88 ; \mathrm{SD}=1.79)$} \\
\hline My children & & & 0.91 & \\
\hline My friends and acquaintances who are involved in sport & & & 0.88 & \\
\hline \multicolumn{5}{|l|}{ 4. Event attractions $(\alpha=0.53 ;$ mean $=0.60 ; \mathrm{SD}=1.40)$} \\
\hline Athletes or teams that would be competing at the event & & & & 0.81 \\
\hline Advertisements in the newspaper or on radio or on television & & & & 0.79 \\
\hline Eigen values & 4.0 & 1.6 & 1.2 & 1.0 \\
\hline Variance explained $(\%)$ & 36.8 & 14.1 & 10.7 & 9.2 \\
\hline Cumulative variance explained $(\%)$ & 36.8 & 50.9 & 61.6 & 70.8 \\
\hline
\end{tabular}

${ }^{\mathrm{a}}$ Factor loadings $<0.3$ have been suppressed. 
Table 3

Rotated Factor Loadings for Perceived Behavioral Control Subscales, Cronbach Alpha Reliability Coefficients, Means and SDs

\begin{tabular}{|c|c|c|c|c|c|}
\hline \multirow[b]{2}{*}{ Factor/Item } & \multicolumn{5}{|c|}{ Rotated Factor Loadings $^{\mathrm{a}}$} \\
\hline & 1 & 2 & 3 & 4 & 5 \\
\hline \multicolumn{6}{|l|}{ 1. Work conditions $(\alpha=0.79 ;$ mean $=3.57 ; \mathrm{SD}=0.63)$} \\
\hline I will be allowed to take adequate meal and rest breaks during my volunteer work & 0.74 & & & & \\
\hline I will be reimbursed for my out-of-pocket expenses (e.g., food, parking, transport) & 0.71 & & & & \\
\hline I will be provided with a safe and secure work environment & 0.68 & & & & \\
\hline I will be or have been provided with adequate uniforms or shirts to complete my volunteer duties & 0.66 & & & & \\
\hline The event organizers will roster enough volunteers to ensure that I can effectively complete my tasks & 0.62 & & & & \\
\hline I will have adequate access to staff support & 0.62 & & & & \\
\hline $\begin{array}{l}\text { It will be quite easy for me to travel between home (or where I am staying) and the venues where I } \\
\text { will be volunteering }\end{array}$ & 0.59 & & & & \\
\hline \multicolumn{6}{|l|}{ 2. Confidence/skills $(\alpha=0.74 ;$ mean $=4.33 ; \mathrm{SD}=0.47)$} \\
\hline I have the confidence needed to be an effective volunteer & & 0.89 & & & \\
\hline I have the skills needed to work effectively in my role as a volunteer & & 0.89 & & & \\
\hline I will have enough free time available to complete the hours that I'm rostered for & & 0.60 & & & \\
\hline \multicolumn{6}{|l|}{ 3. Skills matched $(\alpha=0.59 ;$ mean $=3.81 ; \mathrm{SD}=0.64)$} \\
\hline I will have my assigned tasks matched to my skills and abilities & & & 0.78 & & \\
\hline I had the opportunity to choose the type of position that I wanted & & & 0.68 & & \\
\hline I will receive or have had adequate training for my major responsibilities & & 0.40 & 0.66 & & \\
\hline \multicolumn{6}{|l|}{ 4. Lack of choice about hours $(\alpha=0.69 ;$ mean $=3.11 ; \mathrm{SD}=0.86)$} \\
\hline I might not have much choice about doing more hours than those for which I will be rostered & & & & 0.85 & \\
\hline I might not have much choice about doing fewer hours than those for which I will be rostered & & & & 0.84 & \\
\hline \multicolumn{6}{|l|}{ 5. Other commitments $(\alpha=0.72 ;$ mean $=3.27 ; \mathrm{SD}=0.93)$} \\
\hline I will have few other work commitments that might interfere with completing my volunteer work & & & & & 0.88 \\
\hline I will have few other family commitments that might interfere with completing my volunteer work & & & & & 0.86 \\
\hline Eigen values & 3.9 & 2.4 & 1.6 & 1.4 & 1.2 \\
\hline Variance explained (\%) & 23.2 & 13.9 & 9.3 & 8.2 & 7.3 \\
\hline Cumulative variance explained $(\%)$ & 23.2 & 37.1 & 46.4 & 54.6 & 61.9 \\
\hline
\end{tabular}

${ }^{a}$ Factor loadings $<0.3$ have been suppressed.

Self-reported behavioral dependability loaded on one factor but explained less than $50 \%$ of the total variance (Table 4). Six of the 11 items loaded on factors that could not be interpreted (e.g., "I stayed until the end of my rostered shift completion times") and were dropped from the analysis.
Variables that loaded on attitudinal beliefs, subjective norms, perceived behavioral control, and behavioral dependability factors were used to compute means for each of the respective factors. Because the purpose of this study was prediction, the data were analyzed using a series of SPSS stepwise regression analyses for

Table 4

Factor Loadings for Behavioral Dependability Scale ( $z$ Score), Cronbach Alpha Reliability Coefficient, Mean and SD

Item $(\alpha=0.72 ;$ mean $=0 ; \mathrm{SD}=1.0)$

Factor Loading

I took on additional tasks during my rostered shift(s) without being asked ( $z$ score)

I took on additional tasks during my rostered shift(s) when asked to do so ( $z$ score)

0.76

I stayed longer than my rostered shift time(s) to cover for volunteers who did not turn up for their shift(s) ( $z$ score) $\quad 0.69$

$\begin{array}{ll}\text { Extent to which you feel you could be depended upon during the staging of the event }(z \text { score) } & 0.64\end{array}$

Ratio of completed hours to rostered hours ( $z$ score)

0.48

Eigen value

2.3

Variance explained (\%)

46.7 
all five events combined and for each of the five events, separately. Regression analyses were used to determine the extent to which volunteers' attitudes and beliefs about volunteering for a major sport event were predictive of their level of behavioral dependability. Because the study was largely exploratory, statistical significance was accepted at $p<0.05$.

\section{Results}

Results of the stepwise regression model for the five events combined are summarized in Table 5. The combined events regression model was significant, $F(3,387)=19.6, p<0.001$, and predicted $14 \%(\mathrm{ad}-$ justed $R^{2}$ ) of the variance in behavioral dependability. In the final step of the regression model, three beliefs and attitudes variables were significant predictors of behavioral dependability. Examination of the significant beta values indicated that positive attitudinal beliefs about employment benefits $(\beta=0.30)$ and perceived behavioral control measured as having the confidence and skills to be an effective volunteer $(\beta=0.17)$ were predictive of higher levels of behavioral dependability across all five events (Table 5).

Perceived behavioral control measured as a lack of choice about (more or less) hours than rostered ( $\beta=-$ 0.11 ) was predictive of lower levels of behavioral dependability for the five events combined. None of the subjective norm beliefs were significant predictors of behavioral dependability for the combined events (Table
5). Because the single model was considered a preliminary analysis to determine whether further analysis was warranted, the data were not weighted to correct for differences in the size of the samples between the events.

To further investigate the generalizability of these results, data from each of the events were analyzed in five separate stepwise regression models, the results of which are displayed in Table 6 . All five regression models were significant at $p<0.05$ and they explained between $5 \%$ and $33 \%$ (adjusted $R^{2}$ ) of the variance in behavioral dependability. Of the 14 independent variables (Tables 1,2, and 3), half were significant predictors of behavioral dependability. However, none of the independent variables were significant predictors of behavioral dependability for all five separate events.

The most consistent predictor variable across the five separate events was perceived behavioral control measured as having the confidence and skills to be an effective volunteer. The significant beta weights were 0.34 (Arafura Games), 0.28 (Q500), and 0.27 (PGA). Two independent variables were significant predictors of behavioral dependability in more than one event. Positive attitudinal beliefs about employment benefits had significant beta weights of 0.29 for the FIH and 0.20 for the Q500. Subjective norm measured as distal influence had significant beta weights but in opposite directions of -0.39 for the FIH and 0.28 for the PGA.

Four different independent variables were significant predictors of behavioral dependability for one event each (Table 6). Attitudinal beliefs-negative affect

Table 5

Stepwise Regression of Attitudinal Beliefs, Subjective Norms, and Perceived Behavioral Control on Mean Behavioral Dependability for all Major Events Combined

\begin{tabular}{lccc}
\hline & \multicolumn{3}{c}{ Test Statistics } \\
\cline { 2 - 4 } Independent Variable & Step 1 & Step 2 & Step 3 \\
\hline Attitudinal beliefs_employment benefits $(\beta)$ & $0.33^{* * *}$ & $0.31^{* * *}$ & $0.30^{* * *}$ \\
Perceived behavioral control—confidence/skills $(\beta)$ & & $0.17^{* * *}$ & $0.17^{* * *}$ \\
Perceived behavioral control-lack of choice about hours $(\beta)$ & & & $-0.11^{*}$ \\
Intercept & -1.20 & -2.71 & -2.25 \\
Adjusted $R^{2}$ & 0.11 & 0.13 & 0.14 \\
$F$ (regression) & $42.4^{* * *}$ & $27.0^{* * *}$ & $19.6^{* * *}$ \\
$d f$ & $(1,389)$ & $(2,388)$ & $(3,387)$ \\
$R^{2}$ change & 0.11 & 0.03 & 0.01 \\
$F$ (change) & $47.5^{* * *}$ & $13.3^{* * * *}$ & $5.6^{*}$ \\
$d f$ & $(1,389)$ & $(1,388)$ & $(1,387)$ \\
\hline
\end{tabular}

$* p<0.05$.

$* * p<0.01$

$* * * p<0.001$. 
Table 6

Stepwise Regression of Attitudinal Beliefs, Subjective Norms, and Perceived Behavioral Control on Mean Behavioral Dependability by Major Event

\begin{tabular}{|c|c|c|c|c|}
\hline \multirow[b]{2}{*}{ Independent Variable } & \multicolumn{4}{|c|}{ Test Statistics } \\
\hline & Step 1 & Step 2 & Step 3 & Step 4 \\
\hline \multicolumn{5}{|l|}{ Arafura Games } \\
\hline Perceived behavioral control—confidence/skills $(\beta)$ & $0.41 * * *$ & $0.34 * *$ & & \\
\hline Subjective norm-event/staff volunteers $(\beta)$ & & $0.25^{*}$ & & \\
\hline Intercept & -3.09 & -2.78 & & \\
\hline Adjusted $R^{2}$ & 0.15 & 0.20 & & \\
\hline$F$ (regression) & $14.2 * * *$ & $10.3 * * *$ & & \\
\hline$d f$ & $(1,72)$ & $(2,71)$ & & \\
\hline$R^{2}$ change & 0.17 & 0.06 & & \\
\hline$F$ (change) & $14.2 * * *$ & $5.5 *$ & & \\
\hline$d f$ & $(1,72)$ & $(1,71)$ & & \\
\hline \multicolumn{5}{|l|}{ Federation Internationale Hockey Champions Trophy (FIH) } \\
\hline Subjective norm-distal influences $(\beta)$ & $-0.37 *$ & $-0.39 * *$ & & \\
\hline Attitudinal beliefs_-employment benefits $(\beta)$ & & $0.29 *$ & & \\
\hline Intercept & 0.67 & -0.78 & & \\
\hline Adjusted $R^{2}$ & 0.12 & 0.18 & & \\
\hline$F$ (regression) & $6.4^{*}$ & $5.6 * *$ & & \\
\hline$d f$ & $(1,40)$ & $(2,39)$ & & \\
\hline$R^{2}$ change & 0.14 & 0.08 & & \\
\hline$F$ (change) & $6.4^{*}$ & $4.2 *$ & & \\
\hline$d f$ & $(1,40)$ & $(1,39)$ & & \\
\hline \multicolumn{5}{|l|}{ Queensland 500 V8 Supercar Shell Championship Series (Q500) } \\
\hline Attitudinal beliefs-negative affect $(\beta)$ & $-0.44 * * *$ & $-0.50 * * *$ & $-0.50 * * *$ & $-0.48 * * *$ \\
\hline Perceived behavioral control—confidence/skills $(\beta)$ & & $0.29 * *$ & $0.30 * *$ & $0.28 * *$ \\
\hline Perceived behavioral control-other commitments $(\beta)$ & & & $-0.22 *$ & $-0.21 *$ \\
\hline Attitudinal beliefs-employment benefits $(\beta)$ & & & & $0.20 *$ \\
\hline Intercept & 1.19 & -0.73 & -0.13 & -0.79 \\
\hline Adjusted $R^{2}$ & 0.19 & 0.26 & 0.30 & 0.33 \\
\hline$F$ (regression) & $20.8 * * *$ & $15.9 * * *$ & $13.2 * * *$ & $11.6^{* * *}$ \\
\hline$d f$ & $(1,85)$ & $(2,84)$ & $(3,83)$ & $(4,82)$ \\
\hline$R^{2}$ change & 0.19 & 0.08 & 0.05 & 0.04 \\
\hline$F$ (change) & $20.8 * * *$ & $9.1 * *$ & $5.9 *$ & $4.9 *$ \\
\hline$d f$ & $(1,85)$ & $(1,84)$ & $(1,83)$ & $(1,82)$ \\
\hline \multicolumn{5}{|l|}{ Noosa International Triathlon (Noosa Tri) } \\
\hline Perceived behavioral control-lack of choice about hours $(\beta)$ & $-0.25 *$ & & & \\
\hline Intercept & 1.19 & & & \\
\hline Adjusted $R^{2}$ & 0.05 & & & \\
\hline$F$ (regression) & $5.7 *$ & & & \\
\hline$d f$ & $(1,83)$ & & & \\
\hline$R^{2}$ change & 0.06 & & & \\
\hline$F$ (change) & $5.7 *$ & & & \\
\hline$d f$ & $(1,83)$ & & & \\
\hline \multicolumn{5}{|l|}{ Australian Professional Golfers' Association Championship (PGA) } \\
\hline Subjective norm—distal influences $(\beta)$ & $0.30 * *$ & $0.28 * *$ & & \\
\hline Perceived behavioral control—confidence/skills $(\beta)$ & & $0.27 * *$ & & \\
\hline Intercept & -0.53 & -2.85 & & \\
\hline Adjusted $R^{2}$ & 0.08 & 0.15 & & \\
\hline$F$ (regression) & $10.1 * *$ & $9.7 * * *$ & & \\
\hline$d f$ & $(1,101)$ & $(2,100)$ & & \\
\hline$R^{2}$ change & 0.09 & 0.07 & & \\
\hline$F$ (change) & $10.1 * *$ & $8.6 * *$ & & \\
\hline$d f$ & $(1,101)$ & $(1,100)$ & & \\
\hline
\end{tabular}

$* p<0.05$.

$* * p<0.01$.

$* * * p<0.001$. 
$(\beta=-0.48)$ and perceived behavioral control-other commitments $(\beta=-0.21)$ were significant negative predictors of behavioral dependability for operational volunteers at the Q500 event (Table 6). Subjective norm—event/staff volunteers $(\beta=0.25)$ and perceived behavioral control-lack of choice about hours $(\beta=-$ 0.25 ) accounted for significant amounts of variance in behavioral dependability for the Arafura Games and Noosa Tri, respectively (Table 6). Of the five separate regression models, the Q500 with four significant predictor variables accounted for the most variance in behavioral dependability (adjusted $R^{2}=0.33$ ). The Noosa Tri, with one significant predictor variable, accounted for the least amount of variance in behavioral dependability (adjusted $R^{2}=0.05$ ). On the basis of beta weights, the strongest single predictor variable in the final step of the five regression models was attitudinal beliefs-negative affect $(\beta=-0.48)$ in the Q500 event. Q500 volunteers who had strong negative attitudinal beliefs about being an event volunteer were significantly more likely to have lower levels of behavioral dependability during the staging of the event. This result is perhaps not surprising given evidence of negative attitudes among career volunteers/amateurs whose specialized and necessary voluntary work at motor sport events is taken for granted and underappreciated by race organizers (Harrington et al., 2000).

\section{Discussion}

This study utilized a modified version of the TPB (Ajzen, 1988) to predict the behavioral dependability of operational level volunteers at five major sport events. An elicitation study was undertaken to identify the salient beliefs held by volunteers at major sport events. Behavioral intention was dropped from the analysis because almost all of the participants indicated that they intended to complete all of their rostered shifts and hours. Behavioral dependability was significantly predicted by the attitudinal beliefs of volunteers about major event volunteering, the beliefs of volunteers about the opinions of significant others (referents) about their participation, and the extent to which respondents believed they had control over their experience as a major event volunteer.

For the most part, the independent variables predicted behavioral dependability in expected directions. For example, strong positive and negative attitudes towards major event volunteering predicted higher and lower levels of behavioral dependability, respectively. However, one subjective norm had a significant but opposite influence on volunteer dependability for two events. Normative beliefs about the influence of significant others who were either work colleagues or supervisors or friends outside of sport (subjective norm-distal influences) positively influenced the dependability of the PGA volunteers but negatively influenced the dependability of FIH volunteers. Such a contradictory result might be explained by the differing duration of the events and the subsequent expectations event organizers had of their volunteers. The PGA event required operational volunteers for a maximum of 4 days of which 2 days were over a weekend. The FIH event was staged over 10 consecutive days and ran evening as well as day sessions. There was a significant difference, $F(4,386)=83.5, p<0.001$, between the mean number of rostered shifts at the five events. Using a Scheffe post hoc test $(p<0.05)$, the mean number of rostered shifts of 12.5 for the FIH volunteers was significantly greater than all other events including a mean of 3.5 shifts for the PGA volunteers. This meant that the participation of many FIH volunteers was more likely to be dependent upon perceived support from significant others, including employers and friends, than it was at other events.

There is theoretical support for the results of this study. Perceived behavioral control was a predominant predictor of behavioral dependability. Perceived behavioral control accounted for two of the three significant predictor variables in the combined regression model and accounted for 5 of the 11 significant predictor variables for the five separate event regression models. Consistent with the TPB, there was evidence of internal and external control factors. It was argued earlier in this article that internal control was an approximation of self-efficacy in that it involved perceptions of having the skills necessary to volunteer as well as the confidence to be an effective volunteer. This finding supports Bandura's (1986) social cognition theory, which explicated the importance of self-efficacy in explaining behavior. Two external control variables were also significant predictors of dependability in the expected negative direction. The TPB argued that uncertainty about completing an intended behavior is influenced by the presence or absence of control factors that Ajzen (1988) categorized as internal and external. In this study, two external factors-other commitments and lack of choice about volunteer hours-were significant nega- 
tive predictors of behavioral dependability. Consistent with attribution theory (Zuckerman, 1979), volunteers attributed higher levels of dependability to their perceptions of having the confidence and skills to be an effective volunteer. In contrast, they ascribed lower levels of dependability to external factors such as other commitments and lack of choice about hours.

Theoretically, Ajzen (1988) argued that perceived behavioral control can be a direct influence on behavior or it can influence behavior indirectly through behavioral intentions. Because behavioral intentions were dropped from the analysis in this study only the direct influence of perceived behavioral control could be examined. Perceived behavioral control can predict behavior directly when the behavior is not under complete volitional control and when perceived control is an accurate reflection of actual control (Ajzen, 1988). It is probable that the context in which major event volunteers operate reflects such conditions. Event volunteers are not likely to have complete volitional control over their behavior because they are assigned to particular shifts, hours, and duties according to the needs of event organizers and in a highly formalized context. In some instances they may have to negotiate the scheduling of other commitments (e.g., work or family) to volunteer. The duration of an event in terms of the number of days and the subsequent expectations of event organizers, and the support of significant others or lack thereof, seem to be important factors in determining the dependability of volunteers.

The finding that an attitudinal belief, negative affect, was the strongest predictor $(\beta=-0.48)$ of behavioral dependability in any of the regression models is consistent with evidence that behavior tends to be under attitudinal rather than normative control (Ajzen, 1991). Though consistent with theoretical propositions, this finding contrasted with those of Warburton and Terry (2000), who found evidence that volunteering amongst older volunteers was under normative rather than attitudinal control. To some extent, the measurement of positive attitudinal beliefs in this study incorporated the notion of altruism. Attitudinal belief scale items such as "I expect to feel good about being able to help others, "I anticipate I'll feel good about using my free time in a constructive way," and "I expect to feel as though I've put something back into sport" convey a sense of prosocial thoughts and feelings. Altruism is widely supported as an underlying motive for volunteering (Clary, Snyder, \& Ridge, 1992; Pearce, 1993; Simmons, 1991; Stebbins, 1996; Warburton \& Oppenheimer, 2000).
Throughout the data collection process there was little evidence that event organizers were particularly concerned about managing the dependability of their volunteer workforce. In fact, several event managers were openly critical of their volunteer staff. Rather than address the underlying issue, there was a tendency to minimize potential damage by "overrecruiting" volunteers. This study concentrated on antecedent conditions that may be predictive of volunteer dependability. However, it is evident that volunteer management systems could be improved if volunteer debriefing and feedback procedures were implemented and volunteers were engaged in a process designed to reduce the dissatisfying aspects of their event experience. Improved volunteer management practices might include more specific event and job orientation, job matching, and training that emphasize the development of skills and confidence. Management practices that develop volunteers' beliefs in their skills and abilities seem most likely to influence their level of dependability.

Although this study was based on a recognized theoretical framework, there were several methodological limitations. First, the study relied on self-reported measures of behavioral dependability and respondents may not have accurately recalled their actual behavior or exaggerated their dependability due to social desirability bias. Aside from the motor racing event, due to safety concerns and legal liability, volunteers did not routinely sign-in or sign-out for their shifts. It was not possible to objectively and reliably measure dependability by comparing actual attendance records with the rostered shifts of operational volunteers. Second, there was the potential for nonresponse bias in the sample, thereby limiting the generalizability of the results. Participants who did not respond to both the preevent and postevent surveys were excluded from the study. Nonrespondents may have been less dependable than other volunteers and were potentially underrepresented in the sample. It was not plausible to test this potential bias because behavioral dependability was measured in the postevent survey. Thirdly, behavioral intentions were operationalized too simplistically in this study and were dropped from the analysis. Behavioral intentions are known to be an important mediating variable between attitudinal beliefs and subjective norms and behavior. Finally, due to the limitations of sample sizes within each event, the factor structures of the predictor and dependent variables aggregated the data across all five events. 
Previous studies have argued for and found evidence that major event volunteers represent a distinct category of volunteers who have particular motives that they seek to satisfy through their involvement and volunteer experience at major or special events (e.g., Farrell et al., 1998). This study has extended this work by finding that the behavioral dependability of major event volunteers is influenced by several social and cognitive antecedent variables. It was concluded that the social and cognitive factors that predict dependability at one event were inconsistent with the factors that influence the dependability of volunteers at other major events.

\section{Conclusion and Further Research}

Much of the body of knowledge about the motives and behavior of major or special event volunteers has been built on a number of studies that have concentrated data collection on a single event using cross-sectional research designs (e.g., Andrew, 1996; Elstad, 1996; Farrell et al., 1998; Saleh \& Wood, 1998). The generalizability of findings from such studies is limited and is potentially erroneous. The present study was conclusive about the predictability of volunteer dependability. However, it could not be conclusive about which factors are consistent predictors of the behavioral dependability of major event volunteers. The duration of an event and subsequent expectations placed upon volunteers by event organizers and perceived support of significant others were identified as potentially important influences in such a relationship. Other factors, such as an event's size and structure, its multiple or monosport nature, its location, and perhaps the types of volunteers attracted to particular types of events, should caution researchers about the generalizability of major event volunteer studies. Farrell et al., (1998) argued appropriately the major event volunteers represent a distinct category of volunteers. The present study has demonstrated that major event volunteers may represent more than a distinct category. Consistent with the event framework developed by Jago and Shaw (1998), volunteers ought to be studied within the context of different event categories.

There is a need for replicable research designs and methods, and appropriate theoretical approaches in order to advance knowledge and understanding of what is a key component of major event organization and management. The findings of this study have demonstrated that well-developed and widely utilized theo- ries, such as the TPB, are an important starting point for studies of major event volunteers interested in moving beyond description to more comprehensive and logically reasoned explanations of volunteer behavior. Farrell and her colleagues (1998) have used the empirical work of others to move in the direction of explanatory research. There is room to further develop this body of knowledge through the application or adaptation of the TPB and other theoretical approaches. This study concluded that each of the major components of the TPB were multidimensional constructs and that none of these constructs consistently predicted behavioral dependability. Future studies might test the veracity of these findings and their applicability to major event volunteers in other organizational settings.

Understanding and influencing the behavior of major event volunteers is more complicated than ensuring that the motives of volunteers are satisfied by event organizers. Making the assumption that volunteers are motivated in organizational settings by extrinsic rewards ignores a body of theoretical and empirical research that has found volunteer rewards are derived from participation in the activity itself (Pearce, 1993). Event organizers who place too much emphasis on extrinsic rewards run the risk of reducing the importance of intrinsically rewarding motives such as the enjoyment of the activity of volunteering, interacting socially with other volunteers and event participants, and contributing to the larger social good. Few of the significant predictors of behavioral dependability in this study are likely to be directly controlled by event organizers.

The design of this study has been helpful in understanding the temporal influence of beliefs about volunteering and behavioral dependability, but it cannot argue that it has established causation. There is a need for controlled quasi-experimental or field studies. Future studies based on the TPB also need to ensure that they capture a volunteer cohort with a much wider variety of behavioral intentions. This might be achieved by surveying potential volunteers using a preevent lead time greater than the 2 weeks used in this study.

The unpaid work of major event volunteers tends to be intensive and highly structured, yet people are motivated to become involved in events staged in their community. The use of volunteers is also a way of encouraging community ownership of, and involvement in, major sport events. Event organizers ought to consider the salient beliefs of volunteers if they plan to maximize the dependability of their volunteer workforce. 
The process of maximizing behavioral dependability appears to stem from prerecruitment processes and extends through to the perceived and actual work conditions during the event.

In summary, the influence of behavioral intentions is of theoretical importance in understanding the links between attitudes, beliefs, and behavior within the context of the TPB. However, major event organizers want to know how to recruit volunteers who are likely to be dependable or how they might positively influence the level of dependability of their volunteers once they are on the job. This research has demonstrated that studies with relevant theoretical foundations have the capacity to enhance our conceptual understanding and explanation of volunteer behavior while contributing to the improvement of management practices applied to major sport event volunteers.

\section{References}

Ajzen, I. (1988). Attitudes, personality and behavior. Milton Keynes: Open University Press.

Ajzen, I. (1991). The theory of planned behavior. Organizational Behavior and Human Decision Processes, 50, 179-211.

Ajzen, I., \& Driver, B. L. (1991). Prediction of leisure participation from behavioral, normative, and control beliefs: An application of the theory of planned behavior. Leisure Sciences, 13(3), 185-204.

Ajzen, I., \& Driver, B. L. (1992a). Application of the theory of planned behavior to leisure choice. Journal of Leisure Research, 24(3), 207-224.

Ajzen, I., \& Driver, B. L. (1992b). Contingent value measurement: On the nature and meaning of willingness to pay. Journal of Consumer Psychology, 1(4), 297-316.

Ajzen, I., \& Fishbein, M. (1980). Understanding attitudes and predicting social behavior. Englewood Cliffs, NJ: Prentice Hall.

Andrew, J. (1996). Motivations and expectations of volunteers involved in a large scale sports event-a pilot study. Australian Leisure, 7(1), 21-24.

Astrom, A. N., \& Rise, J. (2001). Young adults' intention to eat healthy food: Extending the theory of planned behaviour. Psychology and Health, 16(2), 223-237.

Australian Bureau of Statistics. (1996). Voluntary work Australia (Cat. No. 4441.0). Canberra: Author.

Bandura, A. (1986). Social foundations of thought and action: A social cognitive theory. Englewood Cliffs, NJ: PrenticeHall.

Biddle, S. J., \& Nigg, C. R. (2000). Theories of exercise behavior. International Journal of Sport Psychology, 31(2), 290304.

Bozionelos, G., \& Bennett, P. (1999). The theory of planned behavior as predictor of exercise: The moderating influence of beliefs and personality variables. Journal of Health Psy- chology, 4(4), 517-529.

Brown, T. J. (1999). Antecedents of culturally significant tourist behavior. Annals of Tourism Research, 26(3), 676-700.

Caldwell, L. L., \& Andereck, K. L. (1994). Motives for initiating and continuing membership in a recreation-related voluntary association. Leisure Sciences, 16, 33-44.

Clary, E. G., Snyder, M., \& Ridge, R. (1992). Volunteers' motivations: A functional strategy for the recruitment, placement, and retention of volunteers. Nonprofit Management and Leadership, 2(4), 333-350.

Courneya, K. S., Bobick, T. M., \& Schinke, R. J. (1999). Does the theory of planned behavior mediate the relation between personality and exercise behavior. Basic and Applied Social Psychology, 21(4), 317-324.

East, R. (1993). Investment decisions and the theory of planned behavior. Journal of Economic Psychology, 14(2), 337-375.

Elstad, B. (1996). Volunteer perceptions of learning and satisfaction in a mega-event: The case of the XV11 Olympic Winter Games in Lillehammer. Festival Management \& Events Tourism, 4, 75-83.

Farrell, J. M., Johnston, M. E., \& Twynam, G. D. (1998). Volunteer motivation, satisfaction and management of an elite sporting competition. Journal of Sport Management, 12(4), 288300.

Fazio, R. H., Powell, M. C., \& Herr, P. M. (1983). Toward a process model of the attitude-behavior relation: Accessing one's attitude upon mere observation of the attitude object. Journal of Personality and Social Psychology, 44, 723-735.

Fishbein, M., \& Manfredo, M. J. (1992). A theory of behavior change. In M. J. Manfredo (Ed.), Influencing human behavior: Theory and applications in recreation, tourism, and natural resources management (pp. 29-50). Champaign, IL: Sagamore.

Godin, G. (1994). Theories of reasoned action and planned behavior: Usefulness for exercise promotion. Medicine and Science in Sports and Exercise, 26(11), 1391-1394.

Goodwill Games. (2001, March 14). Electronic newsletter (8) [E-mail].

Green, B. C., \& Chalip, L. (1998). Sport volunteers: Research agenda and application. Sport Marketing Quarterly, 7(2), 1423.

Harrison, D. A. (1995). Volunteer motivation and attendance decisions: Competitive theory testing in multiple samples from homeless shelter. Journal of Applied Psychology, 80, 371-385.

Harrington, M., Cuskelly, G., \& Auld, C. (2000). Career volunteering in commodity-intensive serious leisure: Motor sport events and their dependence on volunteers/amateurs. Loisir et Société, 23(2), 421-452.

Hausenblas, H. A., Carron, A. V., \& Mack, D. E. (1997). Application of theories of reasoned action and planned behavior to exercise behavior: A meta-analysis. Journal of Sport and Exercise Psychology, 19, 36-51.

Hill, M., Mann, L., \& Wearing, A. J. (1996). The effects of attitude, subjective norm and self-efficacy on intention to benchmark: A comparison between managers with experience and no experience in benchmarking. Journal of Organizational Behavior, 17(4), 313-327. 
Howden, D. (2003, August 17). Countdown to calamity. South China Morning Post.

Jago, L. K., \& Shaw, R. N. (1998). Special events: A conceptual and definitional framework. Festival Management \& Event Tourism, 5, 21-32.

Johnston, K. L., \& White, K. M. (2003). Binge-drinking: A test of the role of group norms in the theory of planned behaviour. Psychology and Health, 18(1), 63-77.

Johnston, M. E., Twynam, G. D., \& Farrell, J. M. (2000). Motivation and satisfaction of event volunteer for a major youth organization. Leisure/Loisir, 24, 161-171.

Kashima, Y., Gallois, C., \& McCamish, M. (1993). The theory of reasoned action and cooperative behavior: It takes two to use a condom. British Journal of Social Psychology, 32(2), 227-239.

Maddux, J. E. (1993). Social cognitive models of health and exercise behavior: An introduction and review of conceptual issues. Journal of Applied Sport Psychology, 5(2), 116-140. [Special Issue: The application of social psychological theories to health and exercise]

Mummery, W. K., \& Wankel, L. M. (1999). Training adherence in adolescent competitive swimmers: An application of the theory of planned behavior. Journal of Sport and Exercise Psychology, 21(4), 313-328.

Norman, P., \& Bonnett, C. (1995). Managers' intentions to be assessed for national vocational qualifications: An application of the theory of planned behavior. Social Behavior and Personality, 23(1), 59-67.

Palmer, C. L., Burwitz, L., Smith, N. C., \& Collins, D. (1999). Adherence to fitness training of elite netball players: A naturalistic inquiry. Sport Psychologist, 13(3), 313-333.

Parker, D., Manstead, A. S., Stradling, S. G., \& Reason, J. T. (1992). Determinants of intention to commit driving violations. Accident Analysis and Prevention, 24(2), 117-131.

Pearce, J. L. (1993). Volunteers: The organizational behavior of unpaid workers. London: Routledge.

Petty, R. E., \& Cacioppo, J. T. (1986). The elaboration likelihood model of persuasion. In L. Berkowitz (Ed.), Advances in experimental social psychology (Vol. 19, pp. 123-205). New York: Academic Press.

Quine, L., Rutter, D. R., \& Arnold, L. (2001). Persuading schoolage cyclists to use safety helmets: Effectiveness of an intervention based on the theory of planned behaviour. British Journal of Health Psychology, 6(4), 327-345.

Rosen, C. S. (2000). Integrating stage and continuum models to explain processing of exercise messages and exercise initiation among sedentary college students. Health Psychology, 19(2), 172-180.

Saleh, F., \& Wood, C. (1998). Motives of volunteers in multicultural events: The case of Saskatoon Folkfest. Festival Management \& Events Tourism, 5, 59-70.

Simmons, R. G. (1991). Presidential address on altruism and sociology. Sociological Quarterly, 32(1), 1-22.

Sydney Organising Committee for the Olympic Games. (2000). About volunteers [Online]. http://www.sydney.olympic.org/ content/volunteers.html/about_volunteers

Steadman, L., Rutter, D. R., \& Field, S. (2002). Individually elicited versus modal normative beliefs in predicting attendance at breast screening: Examining the role of belief salience in the theory of planned behaviour. British Journal of Health Psychology, 7(3), 317-330.

Stebbins, R. A. (1996). Volunteering: A serious leisure perspective. Nonprofit and Voluntary Sector Quarterly, 25, 211-224.

Tabachnick, B. G., \& Fidell, L. S. (2001). Using multivariate statistics (4th ed.). Needham Heights, MA: Allyn \& Bacon.

Tonglet, M. (2002). Consumer misbehaviour: An exploratory study of shoplifting. Journal of Consumer Behaviour, 1(4), 336-354.

Warburton, J., \& Oppenheimer, M. (Eds.). (2000). Volunteers and volunteering. Sydney, NSW: Federation Press.

Warburton, J., \& Terry, D. J. (2000). Volunteer decision making by older people: A test of a revised theory of planned behavior. Basic and Applied Social Psychology, 22(3), 245-257.

Zuckerman, M. (1979). Attribution of success and failure revisited: The motivational bias is alive and well in attribution theory. Journal of Personality, 47, 245-287. 